\title{
Achieving sustainability in agriculture: lessons from Australia
}

\author{
R. Bartel \& E. Barclay \\ University of New England, Australia
}

\begin{abstract}
The scientific evidence for environmental degradation is overwhelming however, it is sometimes difficult to translate this evidence into government and policy action and even more problematic to use it to generate behavioural change. The dynamics of scientific knowledge and the way it interacts with personal beliefs and social norms are complex and regard must always be had for the sometimes competing forces at work. Presently there are two crises enveloping the globe, one financial and the other environmental, which are forcing us to recognise the relationships between past and present human activities and future lives and landscapes. Humanity is presently facing relatively well-documented threats of climate change, land use conflict, desertification, extinctions, food, water and financial (in)security however we are still lacking some basic information about a critical part of the global system: ourselves. It is this gap which this study addressed, by inquiring into the environmental attitudes and behaviours of Australian farmers. In Australia the impacts of environmental change will be severe as it is already the driest inhabited continent on Earth and its high and unique biodiversity is especially susceptible to even minor perturbations in conditions. Impacts on food production will also be severe as approximately $60 \%$ of Australia's land surface is under agriculture and Australia exports twothirds of what it produces. However government initiatives to forestall environmental collapse frequently meet with disagreement from farmers: the sector of the Australian population which might be expected to be most concerned. In Australia the relationship between certain land management activities and environmental sustainability is often contested. From a nationwide survey with 1,926 respondents it is apparent that farmers have a range of views and exhibit a variety of behaviours in relation to environmental sustainability but they also share many attitudes. Many are sceptical about climate change and are resistant to nature preservation and restoration laws. Most landholders appreciate their farm environment but many are also ambivalent about government interference. These findings may be used to build our understanding of the "people part" of the sustainability equation and how we might better integrate scientific and technical knowledge with the experience of farmers and land managers. In order to manage landscapes and achieve sustainability we need to understand natural systems but we also need to understand people.
\end{abstract}

Keywords: environmental degradation, scientific knowledge, agriculture, Australia, environmental change, behavioural change, attitudes. 


\section{Introduction}

Australia's agricultural industry is important economically to Australia and it is also critical to the food security of both Australia and the world. It exports twothirds of production: export earnings for 2009-10 are forecast to be $\$ 32$ billion, a rise from $\$ 31$ billion in 2008-09. Important export commodities are wheat, barley, canola, lupins, peas, rice, raw cotton, sugar and lamb. The value of Australian farm exports is expected to be worth $\$ 34$ billion in 2013-14 (figures in AUD) [1]. It is also the sector which manages the majority of Australia's landscape, occupying $60 \%$ of its 7.7 million square kilometres and accounts for $65 \%$ of Australia's water consumption. Australia's environmental quality and the sustainability of its agricultural industries and the rural (and urban and overseas) communities which depend on them are threatened however: by land degradation and desertification, reduced water availability, climate change, bushfire and flood risks and biodiversity losses occasioned through land clearance To take biodiversity as one example, biological resources provide humanity with food, fuel, shelter, textiles, paper, recreation, pharmaceuticals and cosmetics as well as ecosystem services such as maintaining biogeochemical cycles, breaking down solid, liquid and gaseous wastes and affecting climate via evapotranspiration, respiration, carbon uptake and storage and reducing albedo, at the same time giving us aesthetically pleasing vistas, spiritual uplift and cultural meaning. Land clearance is the chief driver of biodiversity loss and nine of the top 20 land clearance nations in the world are classified as mega-diverse, including Australia [2]. Land clearance is also an important producer of greenhouse gases and a major cause of the chronic decline in the quality of our land and water resources, and the sustainability of both our natural environments and our production landscapes. Although native cover is often seen as a less worthy combatant in the land use competition, biodiversity offers immeasurable benefits (in the sense of being both extreme and largely incalcuable) to agricultural productivity by maintaining soil-types, off-setting and preventing land degradation, providing shelter, shade and grazing to stock, honey and wildflowers, and habitat for the predators of pests and crop pollinators, as well as a barrier to noise and affording privacy and amenity. Some of these benefits may be property-based, others may be felt downstream, and others again down the generations. Although there is great difficulty in ascribing dollar values to ecosystem services, Robertson and Pratley [3] report the following figures (in Australian dollars) for the annual value of the contribution of some Australian systems: \$36 billion for $118,462,300 \mathrm{~km}^{2}$ of forests and woodlands, $\$ 25$ billion for $13,653,399 \mathrm{~km}^{2}$ of wetlands and floodplains, $\$ 132$ billion for $570,246,300 \mathrm{~km}^{2}$ of rangelands, $\$ 10$ billion for $1,122,000 \mathrm{~km}^{2}$ of lakes and rivers and just $\$ 6$ billion for $47,000,000$ $\mathrm{km}^{2}$ of cropland. The true replacement costs of natural systems would require an enormous investment in infrastructure and require heavy reliance on technological solutions. A cost-benefit study by Lockwood and others [4] found that $53 \%$ of north-east Victorian landholders with 6,659 ha of remnant native vegetation spread over a total of 26,058 ha and $82 \%$ of New South Wales Murray catchment landholders with 18,542 ha of remnant vegetation spread over 
195,571 ha were gaining a net benefit from the vegetation. Benefits accounted included the alleviation of dryland salinity and erosion and the cost of carbon dioxide release. Valuations of ecosystem services however are invisible to the market and therefore do not operate to affect decision-making and economic policy. There are obvious disconnects between science and (mainstream) economics.

There are also disconnects between science and behavioural change since Australians are not altering their practices in response to the well documented evidence of environmental collapse. For example, Australia is listed in the top land clearing nations and land clearing continues for urban expansion and agricultural conversion.

There have been evidence-led policy changes but these have been difficult to implement in practice and have met with resistance from lobby groups and the community. Agricultural lobby groups have been particularly vociferous in their criticisms of the impacts of environmental legislation on farmers. This study was undertaken in order to find out what farmers think about environmental sustainability and governance and what practices they are implementing on their farms for environmental health in order to develop better environmental policy in the future.

Over several decades governments have attempted almost continual reform to the regulation of land and water use in Australia. These regulations however have met with great resistance, both from the regulated landholders and the regulatory agencies charged with their implementation. They have also been ineffective, for example water availability has progressively declined and high rates of land clearance have continued since the enactment of land clearance regulation $[5,6]$. Farmers were recruited for the survey as farmers are such a critical element of effecting land management outcomes in Australia.

\section{Methodology}

From 137,968 primary producers as at the 2006 Census, a random sample of 5,235 were selected for a mail survey administered in the winter of 2008 . The sample size was stratified by taking $2 \%$ of the number of farmers by industry and by state listed in the Australian Bureau of Statistics data on Agricultural Commodities. The names of participants were randomly selected from listings of farmers in the Australian telephone directory. The survey contained a series of questions which included attitude statements to which level of agreement could be indicated on a Likert scale of 1 to 5 . A reminder notice and questionnaire were sent to non-respondents after four weeks followed four weeks later by a one-page close-of-survey questionnaire.

\section{Results}

The final sample provided 1248 respondents and their properties for analysis on the main survey and a further 678 respondents to the close-of-survey questionnaire. The main survey sample of 1248 respondents included 993 males 
$(80.4 \%)$ and $242(19.6 \%)$ females. Males were over-represented as approximately one third of Australian farmers are women. The ages within the sample ranged between 21 and 91 years (Mean $57.51 \mathrm{yrs}$, SD $12.28 \mathrm{yrs}$ ). This is slightly older than the national average for farmers of 52 years as at the 2006 Census. The size of the properties ranged from .40 hectares to 833,000 hectares (Median 625ha; Mean 10,585; SD 57,935ha). There were equal proportions of livestock only (39.6\%) and mixed farming operations (39.8\%). Only $16.3 \%$ of properties were cropping only enterprises. Beef was the most common type of production.

Almost all respondents were farm owners (91.6\%) while 4.4\% were farm managers and the remaining $2 \%$ had other arrangements such as share farming. Respondents had been farming their current property between one and 90 years (Mean 37.18 yrs, SD 18.85yrs). Forty three per cent had lived in their district between 20 and 50 years, while $39 \%$ had been there most of their lives or 50 years or more. Only 19 farmers $(1.5 \%)$ were relative newcomers to the district (less than three years). Just over half $(56.6 \%)$ were on land previously owned by relatives.

The greater proportions of farm businesses were family partnerships $(61 \%)$, private or family companies $(18.8 \%)$ or sole operations $(16 \%)$. Just over half $(61 \%)$ received the majority of their total net income from farming, while the remainder were engaged in off farm work or received income from other sources. Equity in farm properties varied between less than half for $4 \%$ of respondents to more than $90 \%$ for $(51 \%)$ of the respondents. The profile suggests that those farmers who were inclined to respond to the survey were more likely to be well established farmers in a sound financial position.

\section{Discussion}

\subsection{Farmer attitudes to environmental law and governance}

The responses to the survey demonstrate that Australian farmers are deeply ambivalent about the role of government in environmental law and environmental management. Many, but not all, believed that most rural properties have some sort of land degradation; whether it is soil erosion, damage to soil structure, die back, and weed infestation, pollution of streams or salinity. Nearly $10 \%$ disagreed and $12 \%$ were unsure. Many farmers are ambivalent however whether there is a place for government in addressing these issues and there is disagreement over their track record in addressing such problems in the past. Over $85 \%$ believed that farmers should be mainly responsible for environmental management on farms and 56\% agreed with the statement that "environmental problems are best managed without government interference." $21 \%$ were unsure and $23 \%$ disagreed.

Surprisingly for such a well-recognised global issue there was little consensus amongst the sample regarding anthropogenic climate change and many regard climate change as nothing other than a part of natural climate variability. There was also scepticism about other environmental issues, with nearly $20 \%$ 
disagreeing that unauthorised land clearance was wrong and nearly $25 \%$ unsure. However some environmental laws and criminalization of activities were approved of: nearly $85 \%$ believed that "people who knowingly pollute the countryside are just as criminal as people who steal." At the same time farmers feel unfairly targeted by regulations and $65 \%$ believe that "environmental laws and regulations are written to keep city people happy."

\subsection{Farmer behaviours}

Environmental practices were performed by many on their farms (see Figure 1 below).

Almost all (98\%) reported at least one type of activity and $42 \%$ of these had received government support for the activities. Many of these activities are clearly of benefit to production, and weed control is prescribed by law. However,

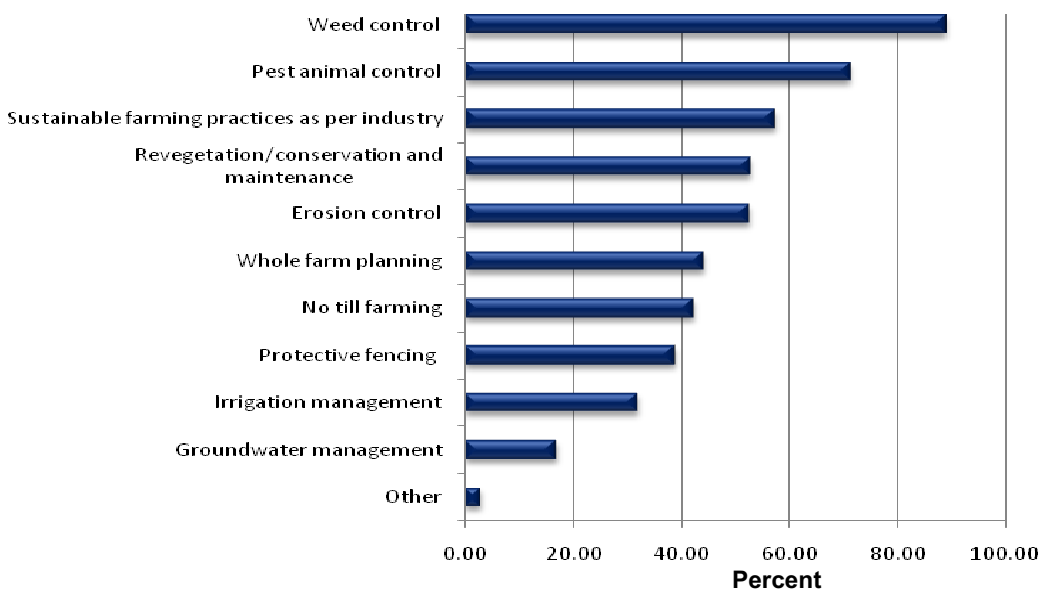

Figure 1: Environmental practices on farms.

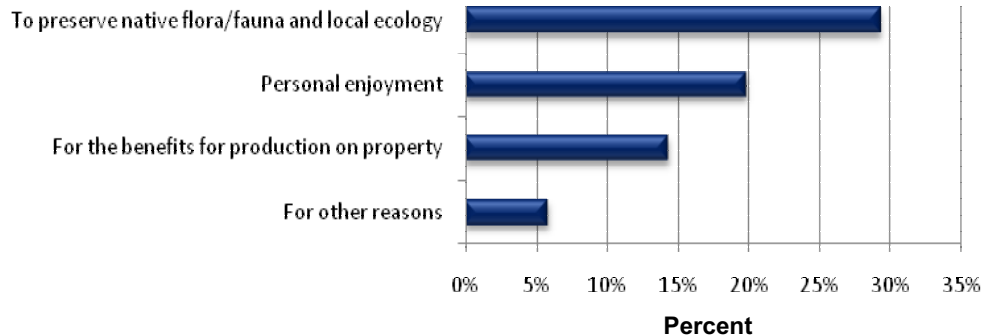

Figure 2: $\quad$ Reasons for preservation of areas. 
over half of the respondents (56.5\%) also reported that they had an area on their property preserved for its environmental benefit. These included fenced areas of remnant vegetation $503(26 \%)$, revegetation/planted trees 221 (12\%), fenced/managed riparian, lake or lagoon areas or wetlands $459(24 \%)$, dams to encourage birds and other wildlife 31 (1.6\%); and habitats $111(5.8 \%)$. The motivations for such preservation behaviours were mainly for environmental benefits but also for the benefits conferred to production (see Figure 2).

\subsection{Farmer cultural values}

Farmers expressed a high degree of attachment to their properties and to country values and ways of life. Farmers are unhappy about drought and structural adjustment but also by changes in land use patterns and changes to their communities wrought by forestry and peri-urban expansion, mining operations, damming of waterways and hobby farming. Farmers viewed alternative land uses as more damaging than farming, with over $40 \%$ agreeing that "hobby farmers have no idea about how to properly maintain the environment on their land" (35\% unsure) and nearly 50\% agreeing that "compared to industries like mining and manufacturing, agriculture has very little impact on the environment." The changes reported in Figure 3 below were viewed as negative by nearly $60 \%$ of respondents, and only $7.7 \%$ deemed them to be positive.

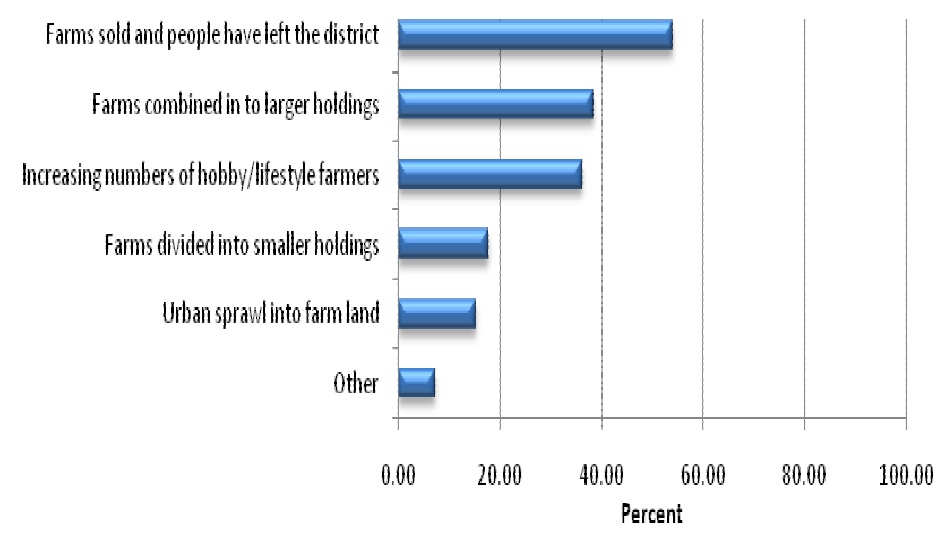

Figure 3: Changes reported in farming districts.

\subsection{Policy implications}

Farmers are doing much for the farm environment but their understanding of environmental issues as apparent in these survey responses suggests there are some gaps between their appreciation of the extent and nature of the problems and how scientists and policy makers may perceive them. The degree of variation in attitudes about environmental issues and government suggests that there are significant challenges for agencies to engender support for environmental laws which attempt to change practices. Farmers may like things 
the way they are, disappointed and unpersuaded by past government action, and may be therefore resistant to change in future. However, the future, if we wish it to remain unaffected by climate change and ecological collapse, depends on us changing our behaviours now. Farmers need to be supported in the actions which they are performing and programmes extended to the wider community so that farmers do not feel that they are being unfairly attacked. As Cummins and Barclay [7] previously found, farmers resent being singularly blamed for environmental degradation and prefer a shared fates approach to dealing with environmental dilemmas which have been created by many and will need efforts similarly spread amongst many if damage is to be ameliorated or prevented.

\section{Conclusions}

People are the key to achieving environmental sustainability because it is the behaviours of people which need to change if humanity is to alter the trajectory of present forecasts of irreversible climate change and ecological collapse. In Australia farmers are the key to effecting change on $60 \%$ of the continent and so their perspectives are critical in determining future policy responses desired to achieve environmental goals. Australian farmers are performing many environmental practices both with and without support from government and this should be further encouraged. Australian farmers are also ambivalent about government regulation and government action and governments must also work to alter these attitudes so that future policy actions may be better received. Governments must work with farmers to better understand their concerns in managing Australian landscapes both for environmental sustainability and for economic productivity: the world depends on it.

\section{Acknowledgements}

The research that forms the subject of this paper was supported by a grant from the Department of the Environment Water Heritage and the Arts: Commonwealth Environment Research Facilities Fund, Canberra Australia.

\section{References}

[1] ABARE, Australian Commodities, March Quarter, 09.1, Commonwealth of Australia, 2009.

[2] Saunders, D., Beattie, A., Eliott, S., Fox, M., Hill, B., Pressey, B., Veal, D., Venning, J., Maliel, M. \& Zammit, C.. Biodiversity, in Australia: State of the Environment 1996, SEAC (State of the Environment Advisory Council), CSIRO Publishing, Collingwood, pp. 4(1-59), 1996.

[3] Robertson, A. \& Pratley, J., From Farm Management to Ecosystem Management, in Agriculture and the Environmental Imperative, eds J. Pratley and A. Robertson, CSIRO, Charles Sturt University, pp. 243-263, 1998.

[4] Lockwood, M., Walpole, S. \& Miles, C., Economics of Remnant Native Vegetation on Private Property, National Research and Development 
Program on Rehabilitation, Management and Conservation of Remnant Vegetation, Research Report 2/00, 2000.

[5] Bartel, R., Satellite Imagery and Land Clearance Legislation: A Picture of Regulatory Efficacy? 9 (1) Australasian Journal of Natural Resources Law and Policy $1-31,2004$.

[6] Bartel, R., Compliance and complicity: An assessment of the success of land clearance legislation in New South Wales, 20(3) Environmental and Planning Law Journal 116-141, 2003.

[7] Cummins, T. and Barclay, E., An evaluation of the Fertcare program, report to the Fertilizer Industry Federation of Australia (FIFA), online at http://www.fifa.asn.au/files/pdf/fertcare/Fertcare\%20Evaluation\%20Report. pdf, 2007. 